\title{
PAISAGEM, LUGAR E CENA EM A FALTA QUE ME FAZ
}

Helena GOMES ${ }^{1}$

\begin{abstract}
Resumo
Refletir sobre a paisagem, neste trabalho, envolve um certo exercício de transgressão disciplinar. Será possível pensar na imagem da paisagem, em seu transporte para a cena de um filme, ou melhor, sua construção em cena? Penso em como o lugar se constrói no filme A falta que me faz. Como se dão os encontros formadores de uma possível partilha? Dissensos, hesitação e partilhas: afetos compartilhados em uma proximidade alcançada pelos corpos que coabitam a imagem. Proponho, nesse caminhar, um deslocamento, da paisagem como uma cena. Ela é aqui vista como um espaço de coabitação. Por trazerem em seu corpo o processo do qual elas se constroem, as imagens do filme tomado apresentam dimensões significantes do sentido de mundo vivido no local que se coloca em cena; processos não cartografados de maneira convencional. $\mathrm{Na}$ análise, o conceito de paisagem é trazido para se pensar o local que ela abriga, transformando-o em lugar para os personagens, e em um segundo nível, construindo-o como um lugar em cena.
\end{abstract}

Palavras-chave: Paisagem; Lugar; Cena; Imagem; Corpo.

\section{PAISAJE, LUGAR E ESCENA EM A FALTA QUE ME FAZ}

\section{Resumen}

Pensar en el paisaje, en este trabajo, implica en un ejercicio de transgresión disciplinaria. ¿Es posible pensar en la imagen del paisaje, su transporte a la escena de una película, o su construcción en la escena? ¿Como se construyó el lugar en la película $A$ falta que me faz. ¿Cómo se llevan a cabo las reuniones de formación en un posible intercambio? Disidencia, vacilación y compartir: afectos compartidos en una proximidad lograda por los cuerpos que conviven en la escena. En el artículo propongo una nueva forma de concebir el paisaje, como una escena. La escena es concebida como un espacio de convivencia. Al incorporar en su cuerpo el proceso a partir del cual son construidas, las imágenes de la película presentan dimensiones significativas del sentido del mundo vivido en el lugar que se pone en escena; procesos no mapeados de manera convencional. En el análisis, el concepto de paisaje lleva a pensar en el lugar que la alberga, así como en un lugar para los personajes y, en outro nivel, como un lugar en la escena.

Palabras Clave: Paisage; Lugar; Enscena; Imagen; Cuerpo.

\footnotetext{
${ }^{1}$ Doutoranda pelo Programa de Pós-Graduação em Geografia da Universidade Federal de Minas Gerais - UFMG. Bolsista CAPES. Pesquisadora do Projeto República, do Núcleo de Pesquisa, Documentação e Memória do Departamento de História - UFMG. E-mail: outrahelena@gmail.com
} 


\title{
LANDSCAPE, PLACE AND SCENE IN \\ A FALTA QUE ME FAZ
}

\begin{abstract}
Writing about the landscape, in the present work, involves the transgression of the discipline. Is it possible to think about the landscape as an image and its transportation to the scene of a movie? I think about how the place is built in the movie "A falta que faz". How do the meetings take place in a possible sharing space? Dissent, hesitation and sharing: affections shared by the bodies that cohabit the image. Therefore, I propose the idea of the landscape as a scene. The scene is seen here as a cohabitation space. The images of the film shows significant parts of the lifeworld of the community; the processes are not mapped in a conventional manner. In the analysis, the concept of landscape is brought to think about the place, as a place for the characters, and on a second level, as a place formed in the scene.
\end{abstract}

Keywords: Landscape; Place; Scene; Image; Body.

\section{INTRODUÇÃ̃o}

Os arranjos espaço-territoriais são construídos em um cotidiano que é vivido nas relações dos sujeitos habitantes com os variados meios, onde paisagens podem ser formadas. Produto e abrigo das interações do homem com os ambientes físicos, elas acolhem, também, os lugares.

Em relação ao conceito de paisagem, ao primeiro pensamento somos levados, por uma tradição de matriz artística e científica ocidental, a relacionála às feições da Terra que os olhos alcançam. As asseverações de Besse (2006) destacam a concepção de paisagem anterior à sua incorporação a um sentido estético e artístico, desenvolvido por um gênero de pintura a partir dos séculos XVII e XVIII.

Na perspectiva apresentada por Denis Cosgrove (1998), no âmbito da geografia humana, a paisagem esteve sempre ligada à cultura, no sentido de composição das feições da superfície terrestre. "A paisagem, de fato, é uma 'maneira de ver', uma maneira de compor e harmonizar o mundo externo em uma 'cena', em uma unidade visual. ” (COSGROVE, 1998, p. 98), uma como composição, em suma.

Na concepção de Cássio Hissa (2009), a paisagem será relacionada às visibilidades dos "corpos do mundo", sendo constituída em um incessante 
movimento de consolidação e transitoriedade. Ela, assim, inscreve e é inscrita em feições materiais, na construção de objetos e de formas do espaço.

A geografia, caracterizada por uma longa fase ideográfica, ancorada pelo estudo das feições dos aspectos físicos da paisagem e como uma "ciência dos lugares" habitados pelo homem, seria atualizada. O sentido indicial das imagens, de muitas naturezas, das quais esse campo disciplinar se ocuparia por muito tempo, sendo deslocado de sua premissa inicial, leva a pensar a imagem, no âmbito da geografia, para além de suas visibilidades imediatas. Assim, como pensar nas paisagens para além de uma categoria geográfica para a descrição de feições físicas dos ambientes?

As ideias de Renata Marquez sobre o tema são inspiradoras. A autora assevera que em seu potencial contato com as artes, praticadas por plataformas diversas, a geografia pode incorporar práticas diferenciadas que traduzem o espaço:

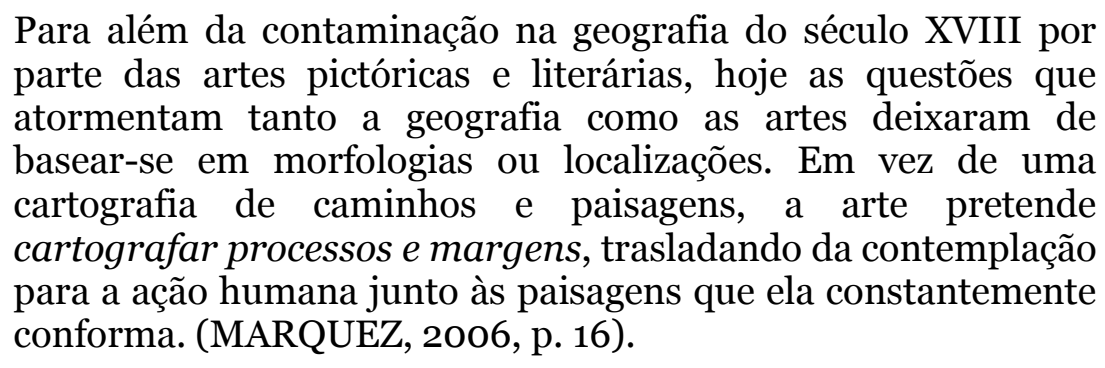

A concepção da paisagem, e de sua natureza imanentemente processual, leva a se pensar a construção do corpo de um filme. Se, em sua construção, ele se estrutura na constituição da dinâmica entre a localidade filmada e os personagens que nele habitam, as relações instauradas para sua realização são, pela mesma via, sua possibilidade de realização; e acabam por definir seu corpo processual e forma final.

\section{IMAGENS E PAISAGENS}

A dimensão composicional, das imagens e das paisagens, é sempre tributária das relações que as fazem. As imagens do documentário "A falta que faz” (2009) de Marília Rocha, apresentam dimensões significantes do sentido de 
mundo vivido no local que se coloca em cena, processos não cartografados de maneira convencional.

Ao nos relacionarmos com o filme, nos planos iniciais algumas feições paisagísticas são logo captadas em planos mais longos para o nosso visionamento. Trata-se de um distrito nos arredores da cidade de Diamantina, Minas Gerais. Primeiros planos do filme: os frames de imagens em movimento que dão a ver os corpos de jovens moças, em grande plano, são como fundo para uma canção entoada em voz feminina. Suas letras dizem de um amor perdido. $\mathrm{O}$ eu-lírico masculino, do convencional compositor angustiado, alude a uma pessoa amada que teria sido seu "começo, meio e fim". As paisagens filmadas nos principiam; ambiente físico, feições morfológicas, flora, solos, aridez. Nossos olhos a classificar. As pequeninas sempre-vivas não se exuberam naturalmente ao olhar desatento. É preciso atenção para vislumbrar as belezas das delicadas e pequeninas flores, para que se descubra a diversidade de suas várias cores. É preciso saber olhar, aproximar.

As cenas trazidas compõem um horizonte que é dado a ver. Alguns quadros que integram os primeiros planos do filme trazem a amplidão dos campos rupestres. As catadoras de sempre-vivas ali presentes são como constituintes de um quadro, que pode corresponder a uma ideia convencional, se evocarmos uma imagem já consolidada e difundida dos tipos de relação entre os habitantes de parte do espinhaço mineiro com seu chão de mundo. No entanto, o que se vê ao longe parece requerer um movimento de aproximação. As relações entre quem habita aquele local não se abrem naturalmente aos que, na lonjura, a espreitam.

Vastidão, vazio, campos, um lugar-sertão. Em que constitui a vida dos que ali habitam? Como os habitantes-personagens se relacionam com aquele espaço, e como o transformam em seu lugar? As cenas iniciais do filme secretam, em planos amplos, o que seria da ordem do pessoal, da escala de cada vida, como um murmúrio vindo de algures, que o movimento de aproximação da câmera tentará recolher.

Quem seriam os melhores interlocutores no processo de conhecimento da localidade de Curralinho? Que personagens trariam à cena a um aspecto singular daquele local? Para as conversações principais entre realizadora e 
personagens, algumas jovens mulheres são as escolhidas. Nas cenas seguintes do filme, começamos a conhecê-las. Da visão panorâmica e distante inicial, somos levados, como que em um movimento de zoom da câmera, agora próxima aos corpos de pessoas, aos seus íntimos entrelaces de uma noite de dança. A câmera que passeia e tateia os corpos em grandes planos quer captar a "conversa no pé do ouvido" que toma lugar na casa de forró. São apresentadas as personagens centrais: Valdênia, Alessandra, Priscila e Shirlene. O filme parece estar em busca da construção de uma cena, de uma relação. $O$ entendimento do lugar-paisagem, desse modo, perpassa a reflexão mesma sobre a vida das jovens, que animam aquela localidade.

Na sequência, no quintal de uma casa, uma das jovens está a marcar seu corpo. Na pele seca da jovem, improvisadas tatuagens de caneta são gravadas. Desenhando organicamente em seu próprio corpo, ela grava em seu corpo com instrumentos dilacerantes. "Essa marca vai ficar de vera", pondera uma personagem à outra que se tatua, que logo responde: "Vai ficar chique!". São desenhadas flores, nomes de uma pessoa presente ou que passou pela história daqueles corpos. Um certo corpo-paisagem a se desenhar, abrigo de faltas e expectativas, já iremos saber. Uma possibilidade é marcar o nome de algum pretendente ou namorado. Porém, as inscrições nos corpos requerem um retoque constante, uma constante dor a ser renovada, a tatuadora observa.

Em "A falta que faz" a figura de mediação, formada a partir da equipe que filma, se faz presente pelo extracampo que entra em cena por suas vozes, mediante as perguntas e as respostas. Há ainda, a ausência. Uma presença insinuada em cena e que acaba sendo tradutora de um vazio, que pouco a pouco conhecemos. Nas possíveis passagens dos desejos às falas, a alteridade que compõe a imagem torna-se, igualmente, fundamental para que o espaço da relação seja uma forma de as personagens tomarem parte do espaço da cena.

Assim, no filme, a personagem da realizadora, Marília, está ausente corporalmente do campo filmado. Sentimos sua presença em cena por sua voz, pelas perguntas feitas por ela, que estabelece o antecampo provocador da cena, que se torna fundamental na relação estabelecida. A voz da realizadora, ao fazer as perguntas às jovens, instiga importantes reflexões e o sentido da "falta" no filme. Em determinado momento, a diretora faz a primeira pergunta: 
"Valdinéia, alguém se mata por amor?" Ao que a interlocutora responde: "Ah, deve se matar né?”, rememorando alguns casos conhecidos. A diretora parece intencionar o tatear de seus desejos através das relações das jovens com seu meio. A partir desse momento, o jogo proximidade, afastamento e hesitação nos diálogos começa a constituir algo como uma relação, que não sendo de uma proximidade sem vacilação, traz a problematização sobre o gesto filmar o outro, quando este traz em sua vida todos os conflitos que a presença do outro pode envolver.

No fazer documentário, é sempre um desafio o ato de apresentar o outro, a "forja" de encontros e pensamentos, conforme assevera Migliorin (2010). Porém, essa intenção seria, prossegue o autor, essencialmente o que move o gesto da realização de um documentário e de onde esse tipo de elaboração se nutre. É do esforço para a construção de um espaço de alteridade - que se encaminha no movimento de se evitar cair nos descaminhos que concebem a figura singular, do personagem, como exemplar - que o documentário busca como sua potência. Segundo tais ideias, o documentário faz da ideia de "mundo na sua diferença" a sua potência de vibração.

Pensando a voz do realizador como um recurso comum na prática documentário, Lima e Maia (2015) dizem que sua inserção no filme pode se dar de várias maneiras, desde uma forma de assumir um lugar de controle, pela narração em over ou pelo endereçamento de perguntas que direcionam a resposta do entrevistado. O "ambiente relacional", criação de um "território afetivo" referido pelas autoras, é formado por afetos e conflitos e pela possibilidade de contato e, às vezes, de sua quase impossibilidade, em $A$ falta que me faz. Esse cambiar faz o filme hesitar. O diálogo é determinante das relações entre personagens e a realizadora, que se vê às voltas com alguma dificuldade as vezes, pelas perguntas remetidas de volta as quem as faz. Nesses momentos, é tensionada a relação entre realizador e os sujeitos documentados. Ela, sendo desigual por sua conjuntura, traz, em seu bojo, as problematizações sobre o papel de quem é responsável pelo filme projeto e se põe a questionar e os que se ocupam o lugar do entrevistado.

Se no filme de Marília Rocha tais problematizações se anunciam, em parte, pelos momentos de tímida hesitação das personagens, elas não parecem 
incorrer em uma renitência sobre o lugar de entrevistadas por elas ocupado. $\mathrm{O}$ impasse envolvido nas respostas das meninas, sua dificuldade de elaboração de determinadas respostas às perguntas a elas endereçadas fazem parte da própria relação construída e que estrutura o filme.

Os corpos compõem o lugar pela presença das jovens. E há, de forma diferenciada, a participação de Marília e sua equipe. A diretora endereça perguntas acertadas a cada uma delas. Ela possui prévio conhecimento sobre a comunidade. Assim, a onipresença da entrevista direta em A falta que me faz inaugura um espaço de direcionamento de perguntas e ideias que pode, a princípio, parecer inquisidor. Há uma clara escolha acerca dos temas das conversas, endereçados em forma de questões às personagens, resultantes das inquietações da realizadora acerca do filme a ser feito e de seu tema. No entanto, com o caminhar das conversas, algo como um campo questionador também se forja a partir das falas das jovens. Em alguns momentos, elas replicam as perguntas à diretora, e essas inflexões acabam por estabelecer uma espécie de reconfiguração da mise-en-scène natural do documentário, ao abalar, de certa maneira, a condição do antecampo questionador. Se forma uma espécie de espaço de coabitação feito de diálogos, a partir das perguntas reenderaçadas à diretora do filme.

Em seu constituir $A$ falta que me faz se mostra bastante sensível à materialidade do ambiente (LIMA e MAIA, 2015, p. 21). O sentido tátil do espaço se constrói pela dinâmica da flutuação entre os amplos planos das jovens moças em meio aos campos que as rodeiam e a captura dos íntimos ambientes constituidores do lugar, como seus lares, as varandas e quartos, onde a maior parte das conversas acontece. Ao buscar a conexão da paisagem com os estados de ânimos internos das personagens, o filme parece querer entender as paisagens por elas construídas. Internas e externas. Se elas "sobem para pensar a vida", procurando os cumes das montanhas e as beiras dos lagos, em momentos contemplativos, é na entrevista direta, mais intimista, que são interpeladas por Marília. Provocadas a responder sobre tais estados, nas acuradamente escolhidas locações, os são lugares afetivos das jovens também se colocam em cena. 


\section{PAISAGEM E CORPO}

Lugar e corpo, produção de corporeidades no cotidiano. É no processo de "conhecer o mundo em sua diferença" que reside a importância de entender o corpo como uma "substância da ação", Eguimar Chaveiro (2012) assevera. Para o autor, a atuação das corporeidades no lugar se relaciona à várias formas de existir nele: "É pela ação, também, que se pratica o lugar pela vivência, desenvolvendo símbolos, manuseando coisas, desferindo representações que alimentam o devir" (CHAVEIRO, 2012, p. 251). Em Falta que me faz, o entendimento das corporeidades se relaciona àqueles trânsitos vividos pelas centrais personagens e suas relações com os ambientes e pessoas que as circundam.

As jovens tateiam, em meio ao ambiente do sertão, suas vidas e as pautam por procuras, ligadas à sobrevivência em meio ao ambiente de atividade mineradora, já um pouco decadente na região, e pelas possibilidades de relacionamentos com os rapazes que habitam a comunidade. Conhecer a vida das jovens moças parece querer dizer, à princípio, questionar e conhecer suas relações com as figuras masculinas presentes ou já ausentes de suas vidas. Filhas de garimpeiros em sua maioria, seu passado, presente e ideia de futuro perpassam por experiências acumuladas e esperadas entre os "homens bicudos". Homens que tomam cachaça, que garimpam, ou que trabalham nas imediações da cidade e que se figuram como as possibilidades de relacionamento amoroso. Mas dos jovens moços pouco sabemos, tão pouco os vemos. A presença desses rapazes é quase toda feita por alusões tão somente nas falas das meninas.

Há também, como referido, a inserção das vozes dos realizadores do filme na cena. Mesmo ausentes corporalmente do campo fílmico, eles se colocam como provocadores dos corpos presentes nele. No entanto, os estrangeiros também provocados. Em certo momento, no alto de um morro, Priscila, questionada sobre seu pretendente, pergunta a um integrante da equipe de Marília sobre a natureza de seu trabalho. $\mathrm{O}$ rapaz diz ser o responsável pela produção do som do filme, ao que ela devolve, exclamando: “Mas só isso?!”. Marília aproveita a deixa e lhe pergunta sobre seu trabalho. 
Resposta vaga novamente; gostar mesmo não gosta não, mas fazer o quê? As perguntas que Priscila remete à equipe também envolvem o amor, ela quer saber sobre as relações conjugais de Canarinho, o técnico de som: "Cê também é bem safadinho, né?”, diz ao saber que ele foi casado por três vezes. Indagada sobre suas relações passadas e presentes, e sobre sua possível condição no momento de retorno da equipe ao local, ela diz, sempre cabisbaixa e com ares de descrença "vamos ver o que destino reserva para nós". Tais cenas compõem, de alguma forma, um ambiente paisagístico próprio, tanto pelo local escolhido pela filmagem, como pela abertura de uma paisagem como expressão de um interior da personagem. A margem da imagem, entrando em cena, constitui uma importante dimensão da instauração da confrontação entre as mise-en-scènes ali presentes e que formam o espaço da cena.

No decorrer do filme, o cotidiano é marcado e dado a ver pelas tarefas diárias das personagens, trazidas em planos em que as moças aparecem recolhendo lenhas para alimentar o fogão de casa, cozinhando, lavando vasilhas, roupas e as colocando para secar no varal. Em outros momentos, as personagens são pegas nadando nos rios e brincando em seus ambientes de vida. A passagem para a fase adulta parece se estabelecer a partir do limiar determinado pelo casamentou ou pela gravidez.

Se o "mundo vivido" das jovens é, pelo amor e pela expectativa, em parte definido por uma espera, nele há, também, algo além da expectativa em relação ao outro. Há dúvidas internas, sobre o papel que seria o natural de seguirem, a de mães e cuidadoras do lar. Algumas têm a certeza sobre este destino quase certo, outras, dúvidas sobre o caminho a seguir. Parece haver certa angústia por sua condição, entre a aceitação e a revolta sobre o papel que devem desempenhar.

Em um momento, uma poesia de amor colada à parede, de autoria de Alessandra e Silvana, é lida. Gestos como este também marcam a vida cotidiana das meninas e conferem um aparente ritmo ao transcorrer de suas existências. Se o amor se faz presente por meio de uma promessa futura para algumas, ele é realizado de forma plena ou parcial na vida de outras. Uma pergunta importante ressoa: Alessandra já teria conhecido algum casamento que deu certo? Reflexiva, ela busca em sua memória as experiências que conhece; com ar de 
conformada assevera: "Hoje em dia é melhor casar por conveniência", acrescentando que é melhor casar tendo já toda a vida organizada.

No prosseguir do filme, vemos planos em que a câmera tateia os paredões dos arredores de Curralinho e as suas largas fissuras: nos afloramentos das cinzas rochas quartizíticas do espinhaço mineiro brancos feixes desgastados demostram o combate do tempo e dos intemperismos nas rochas. Na Gruta do salitre, a ação física inexorável é coexistente às contemporâneas ilustrações nas formações rochosas. Praticadas hoje por quem ali passou, modificam o corpo daquele mundo. São riscos de dizeres diversos, declarações de amor em sua maioria. As ranhuras parecem ser constitutivas do lugar das personagens, observam Lima e Maia (2015). Pelo desejo de expressão de um sentimento ou ideia, os desenhos conformam as aparências das superfícies dos ambientes, ou marcam a passagem de algum corpo por aquele marcado; o gesto de inscrição como um índice de um "aqui-agora" a designar um "lá-depois", na natureza permanecente da vida (LIMA e MAIA, 2015, p. 27).

No prosseguir do filme, o tatear da câmera nos corpos humanos e nos talhes das rochas constitui uma proximidade que será, por todo o filme, equilibrada com o uso de planos afastados. Maia e Lima (2015) observam a formação de tal oscilação como um recurso criado de forma a conferir ritmo à montagem do filme, e que acabam por formalizar os contrastes do filme e os nuances entre o próximo e o distante.

Em uma emblemática cena, acompanhamos a jovem Valdênia conversando com a amiga sobre uma forma de conseguir dinheiro para o enxoval do filho que espera: "Cê já viu diamante assim?", pergunta Marília a uma delas. Os pais, garimpeiros, "tiraram muito diamante", as duas observam. Em suas mãos, são avaliados anéis de cinco reais, que, com sorte, se vendidos renderão duas colchas para abrigar Valdênia e seu filho do frio.

Dissensos, hesitação e partilha; afetos compartilhados em uma proximidade alcançada pelos corpos que coabitam a imagem. As incompletudes da existência parecem corresponder às lacunas constitutivas da vida das personagens, algo que se apresenta nas respostas às vezes pouco convictas das meninas em relação às perguntas feitas por Marília. 


\section{A FALTA CONSTITUTIVA}

Em uma análise que busca aproximar $A$ falta que me faz e o documentário "Morro do céu” (BRA, Dir. Gustavo Spolidoro, 2009), Cláudia Mesquita (2010) diz de um privilégio que ambos os filmes dão à relação entre os corpos e os espaços que nele interagem. A autora assevera que, ambos os filmes, ao trabalharem a composição dos sujeitos filmados pela referência a certo vazio central e por uma ausência, deixam o fora-de-campo influenciar todo delineamento das falas e ações dos personagens. Nesses desenrolares, os locais fílmicos e a relação dos habitantes com eles se estabelecem para além da criação de um mero cenário de filme:

Esse território aberto, vasto, exterior, figura, paradoxalmente, não apenas o espaço que as envolve e situa (isoladas entre as montanhas recônditas), mas a interioridade mesma: vazia, erma, desconhecida, abissal. Em resumo: mais do que algum lugar (a Serra do Espinhaço), vejo neste plano a figuração de lugar nenhum (projetadas, as meninas, alhures, pelo desejo). (MESQUITA, 2010, p.146).

O sentido de lugar aludido por Mesquita aqui é deslocado. Se ele não se reduz à dimensão do local em A falta que me faz - um lugarejo na Serra do Espinhaço - é, de certa forma, produzido por relações interpessoais entre os sujeitos filmados, sendo conformado no sentido de uma ausência sentida e constitutiva nas relações próximas entre as personagens e, igualmente, entre a mediação da realizadora, que a partir dela estrutura as cenas, mediante perguntas sobre as ausências constitutivas daquelas vidas. O tema do amor, em si, confere uma hospitalidade à imagem. As conversas, compreendidas por essas presenças e ausências partilhadas por nós, já dizem do lugar que as jovens ocupam, do lugar que almejam ou que acreditam ter de ocupar.

Acrescento que o lugar nenhum aludido por Mesquita (2010), sendo próprio da relação dos personagens com os espaços que ocupam, é determinante das relações deles entre si e entre personagens e realizadores e acabam por ser constituintes da própria cena do filme. Em minha concepção, o lugar nenhum resulta no lugar em cena, condição mesma de A falta que me faz se constituir como filme. 


\section{CONSIDERAÇÕES FINAIS}

Paisagens da ausência, metáfora sobre a visibilidade da imagem e de sua invisibilidade que se insinua à cena, compondo o visto pelo o que falta, pelos estados de alma dos corpos presentes e táteis no campo do filme. As permanências se juntam à metáfora. Entre planos de vidas, expectativas, frustrações e brincadeiras sobre o porvir, as jovens colocam em cena, por suas falas, suas esperas por concretizações, constituintes de sua vida cotidiana.

Ao final do filme vemos uma estrada. Nos planos finais, uma moça é levada na garupa de uma moto por um rapaz. Ouvimos a canção Je rêve de toi, de Arthur H, embalando o passeio. A falta, delineada pelas falas em todo filme retorna como uma confirmação da importância para sua constituição. No filme feito de escalas, a câmera, tateando os corpos novamente, quer captar o aperto da moça no peito do rapaz no grande plano.

Voltamos às sempre-vivas: uma beleza pequenina e aparentemente delicada que se apresenta como resistente e duradoura. Seriam também os corpos daqueles das jovens, ao que parecem delicados - marcados por sol e cicatrizes e feito de anseios e perspectivas, dotados de ser certa infantilidade de passagem à outra etapa da vida -, como as sempre-vivas, que convidam o olhar a um apuramento maior? Um olhar atento, aberto ao compartilhamento se fez necessário ao seu entendimento, à constituição de um lugar em cena, de uma paisagem a se desenhar.

As paisagens e as imagens de filmes: movimento dos corpos que a integram. A visualidade que elas apresentam é produto do acolhimento do local para os que chegam e que se propõem a conhecê-lo. E em seu conhecer, uma instância imanentemente feita de relações conforma-se, transforma-se em lugar para todos, personagens, realizadores e espectadores, no processo de construção de um lugar em cena. Um simples olhar analítico endereçado às imagens desse filme poderia implicar em um registro objetivo sobre a vida daquelas jovens no espinhaço, sobre seu trabalho como catadoras de sempre-vivas. Mas ao usar uma metodologia de conversa amparada pelo questionamento, assim como pelo gesto de construir um compartilhamento de mise-en-scène com as jovens algo, diga-se, conquistado pelos ímpetos das personagens em questionarem os 
realizadores - Marília Rocha faz um filme revelador, em que o lugar se transforma em uma outra instância criada, compartilhada e multiplicada em cena.

Paisagem e lugar, em A falta que me faz, tornam-se um uno espacial constitutivo das relações que se colocam em cena. Para além da identificação indicial da paisagem que é dada a ver, as relações que ali se desenrolam, agora partilhadas na constituição da cena do filme, fazem com que o lugar já partilhado pelas personagens, seja, pela forma do confronto, da hesitação e do diálogo, compartilhado também por quem chega ao local e por quem as imagens são vistas, o espectador.

\section{REFERÊNCIAS}

BESSE, Jean-Marc. Ver a terra: seis ensaios sobre a paisagem e a geografia. São Paulo: Perspectiva, 2006.

CHAVEIRO, Eguimar Felício. Corporeidade e lugar: elos da produção da existência. In: MARANDOLA JR, Eduardo; HOLZER, Werther; OLIVEIRA, Lívia de. (Org.). Qual o espaço do lugar? Geografia, epistemologia e fenomenologia. São Paulo: Perspectiva, 2012.

COMOLLI, Jean-Louis. Ver e poder: a inocência perdida: cinema, televisão, ficção, documentário. Belo Horizonte: Editora UFMG, 2008.

COSGROVE, Denis. A Geografia está em toda parte: cultura e simbolismo nas paisagens humanas. In: CORRÊA, Roberto L.; ROSENDAHL, Zeny. (Org.). Paisagem, Tempo e Cultura. Rio de Janeiro: Editora UERJ, 1988. P. 84-122.

HISSA, Cássio Eduardo Viana Hissa. Território de diálogos possíveis. In: Compreendendo a complexidade socioespacial contemporânea. O território como categoria de diálogo interdisciplinar. RIBEIRO, Maria Teresa Franco; MILANI, Carlos Roberto Sanchez (Org.). Salvador: EDUFBA, 2009. p. 34-82.

LIMA, Cristiane; MAIA, Carla. A falta que me faz: aproximações possíveis. In: VEIGA, Roberta, MAIA, Carla; GUIMARÃES, Victor (Org.). Limiar e partilha: uma experiência com filmes brasileiros (recurso eletrônico). Belo Horizonte: PPGCOM/UFMG, 2015. P. 14-37.

MESQUITA, Cláudia. A presença de uma ausência: A falta que me faz e Morro do Céu. DEVIRES, Belo Horizonte, V. 7, N. 2, P. 150-161, JUL/DEZ 2010. 
MIGLIORIN, Cezar. Igualdade dissensual: Democracia e biopolítica no documentário contemporâneo. Revista Cinética, 2015. Disponível em: http://www.revistacinetica.com.br/cep/cezar_migliorin.htm.

Recebido em 30 de setembro de 2019 Aceito em 29 de junho de 2020 